\title{
Phocomelia-ectrodactyly-deafness-sinus arrhythmia syndrome
}

INSERM

\section{Source}

INSERM. (1999). Orphanet: an online rare disease and orphan drug data base. Phocomelia-ectrodactyly-deafness-sinus arrhythmia syndrome. ORPHA:2878

Phocomelia-ectrodactyly-deafness-sinus arrhythmia syndrome is characterised by phocomelia (involving arms more severely), ectrodactyly, ear anomalies (bilateral anomalies of the pinnae), conductive deafness, dysmorphism (long and prominent philtrum, mild maxillary hypoplasia) and sinus arrhythmia. It has been described in four patients (a father and his son and a mother and her daughter) from two unrelated families. 